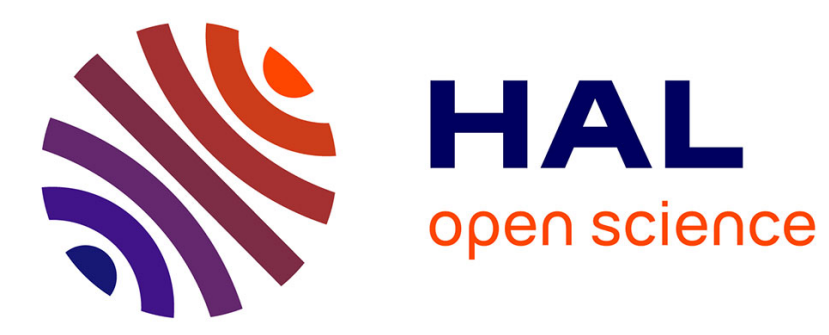

\title{
Influence of Water on the Oxidation of Dimethyl Sulfide by the $\times$ OH Radical
}

\author{
Dominik Domin, Benoît Braïda, Jacqueline Bergès
}

\section{To cite this version:}

Dominik Domin, Benoît Braïda, Jacqueline Bergès. Influence of Water on the Oxidation of Dimethyl Sulfide by the $\times \mathrm{OH}$ Radical. Journal of Physical Chemistry B, 2017, 121 (40), pp.9321-9330. 10.1021/acs.jpcb.7b05796 . hal-01634956

\section{HAL Id: hal-01634956 https://hal.sorbonne-universite.fr/hal-01634956}

Submitted on 14 Nov 2017

HAL is a multi-disciplinary open access archive for the deposit and dissemination of scientific research documents, whether they are published or not. The documents may come from teaching and research institutions in France or abroad, or from public or private research centers.
L'archive ouverte pluridisciplinaire HAL, est destinée au dépôt et à la diffusion de documents scientifiques de niveau recherche, publiés ou non, émanant des établissements d'enseignement et de recherche français ou étrangers, des laboratoires publics ou privés. 
Dominik Domin, Benoît Braïda, and Jacqueline Bergès

J. Phys. Chem. B, Just Accepted Manuscript • DOI: 10.1021/acs.jpcb.7b05796 • Publication Date (Web): 12 Sep 2017

Downloaded from http://pubs.acs.org on September 13, 2017

\section{Just Accepted}

"Just Accepted" manuscripts have been peer-reviewed and accepted for publication. They are posted online prior to technical editing, formatting for publication and author proofing. The American Chemical Society provides "Just Accepted" as a free service to the research community to expedite the dissemination of scientific material as soon as possible after acceptance. "Just Accepted" manuscripts appear in full in PDF format accompanied by an HTML abstract. "Just Accepted" manuscripts have been fully peer reviewed, but should not be considered the official version of record. They are accessible to all readers and citable by the Digital Object Identifier (DOI®). "Just Accepted" is an optional service offered to authors. Therefore, the "Just Accepted" Web site may not include all articles that will be published in the journal. After a manuscript is technically edited and formatted, it will be removed from the "Just Accepted" Web site and published as an ASAP article. Note that technical editing may introduce minor changes to the manuscript text and/or graphics which could affect content, and all legal disclaimers and ethical guidelines that apply to the journal pertain. ACS cannot be held responsible for errors or consequences arising from the use of information contained in these "Just Accepted" manuscripts. 


\title{
On the Influence of Water on the Oxidation of Dimethyl Sulfide by the ${ }^{\circ} \mathrm{OH}$ Radical
}

\author{
Dominik Domin, ${ }^{\dagger}$ Benoît Brä̈da ${ }^{+, *}$ and Jacqueline Bergès ${ }^{+, *}$
}

\author{
${ }^{\dagger}$ Direction de la Recherche Fondamentale, Maison de la Simulation, Bâtiment 565 - Digiteo, \\ Commissariat à l'Énergie Atomique, centre de Saclay, 91191 Gif-sur-Yvette Cedex. \\ *UPMC Université Paris 06, CNRS UMR 7616, Laboratoire de Chimie Théorique, Case \\ Courrier 137, 4 Place Jussieu, 75252 Paris, France. \\ * benoit.Braïda@upmc.fr +33144279657 ; jb@1ct.jussieu.fr +33144279659
}

\begin{abstract}
.
Oxidative stress of sulfur-containing biological molecules in aqueous environments may lead to the formation of adduct intermediates that are too short lived to be experimentally detectable. In this study we have modeled the simplest of such oxidative reactions: the attack of dimethyl sulfide (DMS) by a hydroxyl radical ( $\mathrm{OH})$ to form radical adduct, whose subsequent heterolytic dissociation leads to a radical cation $\left(\mathrm{DMS}^{+}\right)$that is important for further reactions. We have modeled the aqueous environment with a limited number of discrete water molecules, selected after an original multistep procedure, and further embedded in a polarizable continuum model, to observe the impact of the water configuration on the heterolytic dissociation of the radical adduct. Molecular dynamics and quantum chemical methods (DFT, MP2 and CCSD) were used to elucidate the lowest energy structures resulting from the ${ }^{\bullet} \mathrm{OH}$ attack on DMS. Subsequent high level ab initio Valence Bond (BOVB) calculations revealed the possibility for the occurrence of subsequent heterolytic dissociation.
\end{abstract}




\section{Introduction.}

Oxidation of peptides and proteins by ${ }^{\circ} \mathrm{OH}$ radicals is a key event in the development of numerous pathologies and in all events related to radiation biology (radiotherapy, accidental irradiations, etc.). ${ }^{1}$ The consequences of such oxidations are numerous. Among the main targets of these free radicals are Methionine (Met) residues ${ }^{2-9}$ which can be implicated in neurodegenerative diseases as well as in the ageing processes. Their oxidation by ${ }^{\circ} \mathrm{OH}$ has been the focus of numerous experimental and theoretical studies these last thirty years. In particular, the nature of the transient species has been investigated but controversies still exist about their structure. The adduct formation (addition of ${ }^{\circ} \mathrm{OH}$ on the $\mathrm{S}$ atom) appears to be the most favorable, but the corresponding adduct is very short-lived (less than a few microseconds). ${ }^{7}$ The formation of 2 -center-3-electron $(2 \mathrm{c}-3 \mathrm{e})$ bonded radicals ${ }^{10}$ in their cationic forms from Met residues have been observed by several experimental means, and proved stable by theoretical calculations in the gas phase or including the implicit solvent. ${ }^{11-13}$

The stability of the adducts and their dissociation process is of critical importance for the understanding of the oxidation mechanisms of sulfur containing molecules. Recently, several new theoretical studies that used various DFT and ab-initio methods along with the IEFPCM solvation model were applied to study the first steps of the dissociation mechanisms for Sulfuramino residues, methionine (Met), cysteine (Cys) and dimethylsulfide (DMS). ${ }^{14-20}$ The authors considered that one of the major mechanisms is the electron transfer between Met and ${ }^{\circ} \mathrm{OH}$ in the adduct, followed by heterolytic dissociation leading to the formation of the radical cation Met•+.

The ionic 2c-3e bond in general has been the subject of many fundamental theoretical studies. $^{21-33}$ However, these studies mainly focused on ionic $2 \mathrm{c}-3 \mathrm{e}$ bonded systems, with fewer studies on the neutral SO bonds formed in the adducts. ${ }^{34-35}$ In particular, in reference 34 the (2c3e) SO bonds of different radicals was carried out using various computational methods (BH\&HLYP, MP2 and CCSD(T) the possibility of the direct attachment of ${ }^{\circ} \mathrm{OH}$ to $\mathrm{S}$ atom in 
neutral radicals was analyzed with the ELF method ${ }^{36-39}$ and the $2 \mathrm{c}-3 \mathrm{e}$ character of the SO bond in DMS-` OH was established.

The aim of the present work is to use appropriate theoretical tools to shed light on the ${ }^{\bullet} \mathrm{OH}$ radical addition and its dissociation in an advanced solvation model involving explicit water molecules. For this purpose dimethyl sulfide (DMS) has been selected, because it is the simplest organic sulfide to model the oxidation of sulfur in Met. ${ }^{40-50}$ The presence or absence of stabilizing hydrogen bonds has to be carefully checked, since such bonds may modulate the ${ }^{\circ} \mathrm{OH}$-adduct stability. Many previous ab initio calculations were performed on systems of water-assisted mechanisms in order to study the influence water molecules on relatively simple reactions. One of the earlier of these studies concerned the amide hydrolysis. ${ }^{51}$ In that study a water-formamide cluster was embedded in an implicit continuum solvent model and the thermodynamics of the reaction pathway were calculated. Other previous studies of solvation effects used various strategies to sequential add water molecules to small water clusters that microsolvate the solute. ${ }^{52-56}$ The results of these calculations compared favorably to gas phase experimental data when available. Other groups have successfully used QM/MM embedding methods to model solvation in the liquid phase (for example the QMCF method used by Rhodes and coworkers ${ }^{57-}$ $\left.{ }^{59}\right)$.

The oxidation of DMS and Met by $\mathrm{H}_{2} \mathrm{O}_{2}$ resulting in the formation of MetSO and $\mathrm{H}_{2} \mathrm{O}$ has been studied previously ${ }^{41-42}$, using respectively an implicit solvation (PCM) model, and a QM/MM approach to describe the solvent classically. However, because the two dissociation channels of MetSOH, i.e. the "homolytic" (dissociation to DMS + ${ }^{\circ} \mathrm{OH}$ ) and the "heterolytic" (dissociation to $\left.\mathrm{DMS}^{\bullet+}+{ }^{-} \mathrm{OH}\right)$ channels generate neutral and ionic species, respectively, a more realistic solvation model involving in particular a quantum mechanical treatment of the first solvation shell may be of great importance for this reaction. We have thus used a multi-step methodology in order to carefully design a solvation model that describes the most important solvent water molecules quantum mechanically, while remaining tractable with current computer programs and resources. Similar mixed explicit-implicit solvation models have been successfully used in the past by other researchers to describe the influence on of solvation on chemical reactivity and spectroscopy. ${ }^{60-64}$ It must be noted that in this study we focused on the non-entropic energies of the solutes. Ab initio Valence Bond BOVB calculations were performed since the theory that 
combines high accuracy with wide interpretative capabilities. This high level method is particularly suited to study resonant situations, like in the present case, the DMS- $\mathrm{OH}$ system which from equilibrium to the dissociation limit could be described by either two neutral (DMS $\left.+{ }^{\bullet} \mathrm{OH}\right)$ or two ionic $\left(\mathrm{DMS}^{\bullet+}+\mathrm{OH}^{-}\right)$interacting fragments.

\section{Computational details.}

The multistep methodology is briefly outlined in the following, and described fully (including details concerning the MD simulation) in the Supplementary Information (SI). All of the purely QM (DFT) calculations were carried out with the Gaussian 09 suite of programs. ${ }^{65}$

Step one: DFT geometry optimizations of adducts of sulfur containing molecules were carried out using the BH\&HLYP and PBE0 functionals, together with $631 \mathrm{~g}(\mathrm{~d})$ and $6-311+\mathrm{g}(\mathrm{d}, \mathrm{p})$ basis sets, and they used the CPCM implicit solvent model. ${ }^{66}$ The use of two functionals and two basis functions provides some information about how the choice of basis sets and functionals may impact the optimized geometrical parameters. In particular, the BH\&HLYP functional has been shown to well reproduce the bond distances in two-center three-electron bonds, ${ }^{67}$ a type of bonding that most likely occurs in SO adducts, as we will see later. The CPCM model was used to enable comparisons with previous calculations that have been carried out using the same solvent model.

Step two: MD simulations, with geometries of the solute molecules taken from the previous step and kept fixed, were performed with an environment of a very large number of explicit water molecules, i.e. more than 2000 water molecules in each periodic boundary condition unit cell. The CHARMM CGenFF 3.0.1 force field was used for these solute molecules and the rigid CHARMM modified TIP3P water model (see SI for details). The molecules were solvated with $20 \AA$ of TIP3P water in each direction. For the charged species, the force field parameters were obtained for the analogous neutral species and the net formal charge was placed on the sulfur atom. In a second stage of this "step 2", from these MD simulations a nanodroplet of $\sim 70$ solvent water molecules is selected and further BH\&HLYP partial geometry re-optimizations were carried out using the smaller $6-31+\mathrm{G}^{* *}$ basis set and a PCM explicit solvation model to account for the bulk water. From the latter, only the very few water molecules directly in interaction with 
the active site of the solute, i.e. the sulfur atom of DMS and oxygen atom of the ${ }^{\circ} \mathrm{OH}$ moieties, supposedly the most chemically important water molecules of the first solvation shell, will be retained and used in subsequent highest level quantum chemistry calculations.

Step three: further geometry optimizations using Gaussian09 has been carried out with the super system made of the solutes surrounded by a few (4-5) explicit water molecules as selected in the previous step and further embedded into an implicit solvent (CPCM). Both the BH\&HLYP functional and the MP2 method were used in conjunction with the larger $6-311+\mathrm{g}(\mathrm{d}, \mathrm{p})$ basis set.

Step four: Starting from both the BH\&HLYP and MP2 optimized geometries of the super systems (DMS, ${ }^{\circ} \mathrm{OH}, \mathrm{DMS}^{\circ} \mathrm{OH}$ and explicit water molecules), the S...O distance was reoptimized at the CCSD level. In this step, the $6-311 \mathrm{G}(2 \mathrm{~d}, 2 \mathrm{p})$ basis set was used on the two atoms that make the $2 \mathrm{c}-3 \mathrm{e}$ bond, i.e. the sulfur atom of DMS and oxygen atom of ${ }^{\circ} \mathrm{OH}$, and the 6$31 \mathrm{G}(\mathrm{d})$ basis was used for the other atoms. This SO bond distance re-optimization consisted of rigid scans where the SO bond is changed by increments of $0.02 \AA$ while keeping all other geometrical parameters fixed, and a following parabolic fit on the five lowest CCSD energy values to determine the CCSD re-optimized SO bond distances. These calculations were performed in presence of the CPCM continuum solvent. These geometries will be referred to as BH\&HLYP/CCSD and MP2/CCSD geometries in the following.

Step 5: In order to grasp more insight into the nature of the bonding between DMS and ${ }^{\circ} \mathrm{OH}$, high level $a b$ initio Valence Bond calculations were performed with the BOVB method, ${ }^{68-69}$ that includes both static and differential dynamical correlation, using the XMVB 2.1 program. ${ }^{70-73}$ The BOVB approach is presented in more detail in the SI. Single point BOVB calculations on both BH\&HLYP/CCSD and MP2/CCSD optimized geometries for the super system made of the substrate and four explicit water molecules have been carried out using the same combination of basis sets as in step four. The PCM solvation model was used during the BOVB calculations to implicitly describe the outer solvation shells.

\section{Results.}

\section{Benchmarking of substituent effects by DFT methods}


The influence of substituents $\mathrm{X}$ on the SO bond characteristics (SO distances, spin densities) in the $\mathrm{X}_{2} \mathrm{~S}-{ }^{\circ} \mathrm{OH}$ adducts $\left(\mathrm{X}=\mathrm{CH}_{3}, \mathrm{CO}_{2} \mathrm{CH}_{3}, \mathrm{CO}_{2} \mathrm{HNH}, \mathrm{CONH}\right)$ are tested with the PBE0 and BH\&HLYP DFT functionals, that what were previously used for studying radicals. The results of spin densities and S-O distances are summarized in Table 1.

----- insert table 1 near here -----

Several conclusions can be drawn from Table 1 . First, the attack of the ${ }^{\bullet} \mathrm{OH}$ radical on the $\mathrm{S}$ atom produces (within a given methodology) the same optimized S-O distance and the same spin density sharing regardless of the substituent. Second, the S-O distance of 2.31-2.36 $\AA$, as well as the spin density distribution that is largely shared between sulfur and oxygen, are both typical of a neutral 2-center-3 electron (2c-3e) bond, in agreement with a previous topological study of the neutral $(2 \mathrm{c}-2 \mathrm{e}) \mathrm{S}-\mathrm{O}$ bond by one of us. ${ }^{34}$ This point will be further developed in the following. Furthermore, it has been shown that for $2 \mathrm{c}-3 \mathrm{e}$ bonds the DFT functional that best reproduces the geometries and bond energies is the BH\&HLYP "half and half" hybrid functional. ${ }^{67}$ With this functional, the SO bond distances decreases by as much as $0.13-0.14 \AA$ when moving from the 6$31 \mathrm{G}(\mathrm{d})$ basis set to the larger $6-311+\mathrm{G}(\mathrm{d}, \mathrm{p})$ basis. As a consequence, we have used geometries from the BH\&HLYP/6-311+g(d,p) level of theory for subsequent MD calculations.

\section{Analysis of the water solvation from MD simulations.}

The MD simulations corresponds to the "step 2" of the multi-step procedure presented in the "Computational Details" section in the route of creating an accurate and realistic solvation model of the species being study, however, as we will see below, the MD simulations also provide insightful information on the structure of the water solvation shells around the different solutes up to the bulk water, and determination of the most important water molecules hydrogen bonded to the solutes.

The MD simulations were performed using the previously optimized BH\&HLYP/6$311+\mathrm{g}(\mathrm{d}, \mathrm{p}) / \mathrm{CPCM}$ geometries of the solutes (DMS, DMS adduct, DMS radical cation, hydroxyl radical and hydroxide anion), and more than 2000 explicit (rigid TIP3P) water molecules, see "Computational Details" of the SI for the complete methodology used. To analyze the water arrangements that were sampled in the 1ns NPT simulations, we have plotted water radial 
distribution functions, $\mathrm{g}(\mathrm{r})$, from: i) the oxygen atoms of both $\mathrm{DMS}-{ }^{\bullet} \mathrm{OH}$ and ${ }^{\bullet} \mathrm{OH}$, and ii) the sulfur atoms of both DMS and DMS- ${ }^{\circ} \mathrm{OH}$

The water radial distribution functions, around oxygen atom of DMS- ${ }^{\circ} \mathrm{OH}$ and that of the hydroxyl radical and around sulfur atom of DMS- ${ }^{\circ} \mathrm{OH}$ and that of DMS, are calculated from $1 \mathrm{~ns}$ trajectories of our NPT simulations and presented in Fig. 1. So that radial distribution functions were reasonably smooth, snapshots were extracted every 1ps and the radial distribution functions were calculated on grids with a spacing of $0.1 \AA$.

----- insert figure 1 near here -----

Unsurprisingly, we can see in Fig. 1a) that both the DMS- ${ }^{\circ} \mathrm{OH}$ adduct and the hydroxyl radical show peaks in the water radial distribution function at similar radial distances from the solute oxygen atom. The first small peak occurs for both at roughly $2.15 \AA$, is slightly less high for the DMS- ${ }^{-} \mathrm{OH}$ adduct compared to the hydroxyl radical. The next peaks in the water radial distribution functions occur at $3.35 \AA$ for the $\mathrm{DMS}-{ }^{\circ} \mathrm{OH}$ adduct and $3.25 \AA$ for the hydroxyl radical, with the latter pick being noticeably larger. These peaks correspond to an average of about 3 water molecules for the DMS- $\mathrm{OH}$ adduct and 4 waters for the hydroxyl radical.

In Fig. 1b), we can see that, for both DMS and DMS- ${ }^{\bullet} \mathrm{OH}$ alike, the first water molecules start appearing $2.5 \AA$ away from the sulfur atom. The solvation description around the sulfur atom of the DMS- ${ }^{-} \mathrm{OH}$ adduct is very similar to that around neutral DMS. Around $3.65 \AA$ there is a hint of another peak corresponding to an average of 2-3 water molecules.

While the larger water clusters may be more realistic for describing the solvation about the solute, it is likely that only water molecules that are close enough to the solute to form strong to moderate hydrogen bonds with the solute will have a noticeable effect on the electronic structure of the solute. Besides, given the small solute sizes in this study, very weak $\mathrm{C}-\mathrm{H}$ hydrogen bonds $^{74}$ will be inconsequential compared to the strong hydrogen bonds that water makes with the sulfur and oxygen atoms of DMS and the DMS- ${ }^{\circ} \mathrm{OH}$ adduct. Therefore, it is only critical to have correct number of water molecules with about $4 \AA$ of the sulfur and oxygen atoms, and much less important to have the correct number of water molecules around the methyl groups. 
It must be noted that other groups have developed techniques for finding the most chemically relevant water molecules near a solute rather than brute force including all the water molecules in the first two solvation shells (as was done by Rhode and coworkers for atomic ions). ${ }^{57-58}$ Sequential adding water molecules to various sites and optimizing the geometry followed by high-level quantification of the thermodynamic stability of the various configurations was an approach pioneered by Perpète and Jacquemin. ${ }^{52-56}$ While this method is elegant for gas phase microsolvation, it is conceivable that it may converge on water arrangements nearest to the solvent that are far less stable in the condensed liquid phase than in the gas phase. Hence our approach of going from a large number of water molecules down to a few water molecules is arguably a little more conceptually satisfying and requires far less computational effort.

\section{High level optimization of solutes with explicit quantum water molecules}

As a result of the previous steps, we have come to the conclusion to restrict the number of water molecules that should be treated quantum mechanically to those that are in direct interaction with the active site (sulfur and oxygen atoms) substrate, thus forming the first hydration shell. As an initial guess for those water molecules, several snapshots were extracted from the MD simulations considering only the water molecules included in spheres of $2.60 \AA$ radius from the sulfur and oxygen of the solutes considered (DMS, DMS- $\left.{ }^{\circ} \mathrm{OH},{ }^{\circ} \mathrm{OH}\right)$. The optimization of these two individual reactants, independently embedded in the implicit CPCM solvent model, were carried using the BH\&HLYP/6-311+G(d,p) level of theory. The $s$ representing the final optimized geometries of these super-systems are displayed in Table 2.

Mixed implicit-explicit solvent models have been shown by Antonczak and others to be problematic for estimating the entropic contributions to thermodynamic properties, indeed for each water molecule treated explicitly it was estimated that the entropic would increase by 10$12 \mathrm{kcal} / \mathrm{mol}$ regardless of its interaction or lack of interaction with the solute. ${ }^{51,75}$ Since we do not use the mixed model for evaluating free energies, thermodynamic properties or quantifying solvent-solute interaction energies and only focus on the molecular properties of the solute this is not likely to be a serious issue.

insert table 2 near here 
What came out from the geometry optimizations is that, when six (respectively four) water molecules are used to solvate the DMS (respectively the $\mathrm{HO} \bullet$ ), all the water molecules are linked together by H-bonds, but some of them are only linked with other water molecules and do not appear to interact with the solutes. As a consequence, we have further reduced the focus by considering only three, and then two water molecules surrounding the DMS, selecting water molecules at a distance less than $4 \AA$ from the sulfur atom of the DMS; and two water molecules surrounding the $\mathrm{HO}^{\circ}$ radical, selecting water molecules located at a distance less than $2 \AA$ from it. As a result, only the clusters $\mathrm{DMS}+2 \mathrm{H}_{2} \mathrm{O}$ and $\mathrm{HO}^{\circ}+2 \mathrm{H}_{2} \mathrm{O}$ displays, after geometry optimization, solvent molecules directly interacting with the substrate.

As the adduct DMS- $-^{\circ} \mathrm{OH}$ is concerned, table 3 displays the optimized geometries obtained at the BH\&HLYP/6-311+G(d,p)/CPCM and MP2/6-311+G(d,p)/CPCM, when five (top) and four (middle and bottom) water molecules are embedded in the implicit solvent. Basically, both MP2 and BH\&HLYP levels of theory conclude that the fifth water molecule has no direct connection with DMS or ${ }^{\bullet} \mathrm{OH}$, as it can be seen in the middle column of table 3. In particular, both the geometry and spin densities on the bonded sulfur and oxygen come out to be almost identical at the BH\&HLYP level whether four or five solvent molecules are used. The major differences between the two methods are the SO bond lengths that differ significantly, and come out to be much shorter with the MP2 method than when using the BH\&HLYP functional (2.16-2.21 instead of $2.31 \AA$ ). It is however well known that approximate density functionals tend to overestimate the bond length in $2 \mathrm{c}-3 \mathrm{e}$ bonds, ${ }^{67}$ while the MP2 method tends to underestimate the $2 \mathrm{c}-3 \mathrm{e}$ bond distance in some cases. ${ }^{76-77}$ The BH\&HLYP also provides a more even sharing of the radical between the bonded sulfur and oxygen atom than the MP2 method, as illustrated by the spin density values on theses atoms displayed in Table 3.

It appears that four water molecules are enough to describe the first solvation shells around the active sites of the solute from equilibrium (DMS- ${ }^{\circ} \mathrm{OH}$ adduct) to dissociation limit. Besides, it can be noted that the geometries obtained with the BH\&HLYP method are similar to either the solute DMS- ${ }^{\circ} \mathrm{OH}+4 \mathrm{H}_{2} \mathrm{O}$ embedded in a $\mathrm{CPCM}$, or surrounded by the explicit solvent as it was done in QM/MM calculations (see Table 4 in SI). This validates our choice to use the DMS- 
${ }^{\circ} \mathrm{OH}+4 \mathrm{H}_{2} \mathrm{O}$ super system with more sophisticated ab-initio methods such as CCSD or BOVB with the water bulk represented by the implicit solvent (see also the SI).

----- insert table 3 near here -----

To settle the issue of the contrasted SO bond distances and spin densities found with the BH\&HLYP and MP2 methods, we have performed further CCSD geometry re-optimization of the SO bond distance only, starting from the full geometry optimized structures obtained at both the BH\&HLYP and MP2 levels. The exact procedure used for the S-O bond distance optimization is described in the computational details section, and results displayed in table 3 (bottom). At the CCSD level, the SO bond distances is largely reduced from the original BH\&HLYP values, and slightly increased as compared with the original MP2 value, to values of 2.19 and 2.22 for the MP2/CCSD and BH\&HLYP/CCSD geometries respectively. The sharing of the spin densities between the bonded sulfur and oxygen, on its side, seems to depend not only on the SO bond distance but also on the overall geometry of the DMS- ${ }^{\circ} \mathrm{OH}+4 \mathrm{H}_{2} \mathrm{O}$ super-system, as well as on the location of the solvating water molecules also. However, in both final geometries the radical appears to be largely shared between the sulfur and oxygen centers, potentially indicative of a resonant $2 \mathrm{c}-3 \mathrm{e}$ bond, a point that will be tackled in the following section.

----- insert table 4 near here -----

The table 4 displays from bond dissociation energies of DMS-OH into the respective neutral DMS and ${ }^{\circ} \mathrm{OH}$ fragments, for different solvation models and levels of theory. The explicit solvation model provides at the BH\&HLYP level a zero Kelvin BDE some $\sim 2 \mathrm{kcal} / \mathrm{mol}$ larger than the implicit model, which is consistent with a shorter bond length obtained with the former model. In addition, the BDE at the MP2 level (using the MP2 optimized geometry appears to be quite significantly larger than at the BH\&LYP level. Last, it should also be noted that the "homolytic" dissociation (to DMS $+{ }^{\circ} \mathrm{OH}$ ) is energetically more favorable than the "heterolytic" dissociation (to $\mathrm{DMS}^{\bullet+}+{ }^{-} \mathrm{OH}$ ), by some $26 \mathrm{kcal} / \mathrm{mol}$ at the BH\&HLYP/6$311+\mathrm{G}(\mathrm{d}, \mathrm{p}) / \mathrm{CPCM}$ level of theory, with both DMS and ${ }^{\circ} \mathrm{OH}$ fragments (neutral or ionic alike) solvated by two explicit water molecules. Looking at this value alone one might be tempted to 
rule out the heterolytic mechanism, however it will be insightful to inspect more closely the electronic structure in the solvated DMS- ${ }^{\circ} \mathrm{OH}$ adduct, as we will see in the following section.

\section{Valence Bond analysis.}

When an $\mathrm{HO}^{\bullet}$ radical attaches to the lone pair of a less electronegative atom like sulfur, two types of interactions may arise: either a weak electrostatic interaction, or a stronger resonating three electron bond. The conditions for a stable sulfur-oxygen three electron bond have been already studied in the past. ${ }^{35}$ Because, as will be explained below, it can be postulated that only when a $2 c-3 e$ bond occurs that a heterolytic dissociation may take place, the main characteristics of this interaction is recalled here.

Two-centers three-electron (2c-3e) bonds have originally been described within Valence Bond (VB) theory by Pauling, ${ }^{78}$ as arising from the resonance interaction between two VB structures that are connected by the shift of one electron. This type of interaction may arise when one fragment having a radical electron binds a second fragment having a lone pair. Prototype examples of cationic, anionic and neutral three-electron bonds involving a sulfur atom, as depicted in Scheme 1, are: a) the $\left[\mathrm{R}_{2} \mathrm{~S}\right]_{2}{ }^{+}$cation dimer (where $\mathrm{R}$ could be an alkyl group or any other substituents), b) the disulfide[RS $]_{2}{ }^{-}$anion, that appears as long-living intermediates in bio(in)organic reactions involving reduction of a disulfide bridge, and: c) the adduct coming from the interaction of the $\mathrm{HO}^{\circ}$ free radical with a lone pair of a sulfur atom in a neutral fragment. The two-structures resonating VB description for these three prototype cases is displayed in scheme 1.

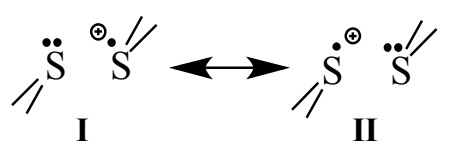

a)

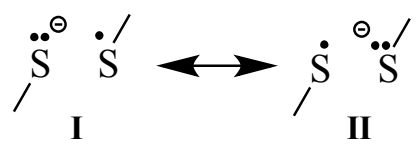

b)

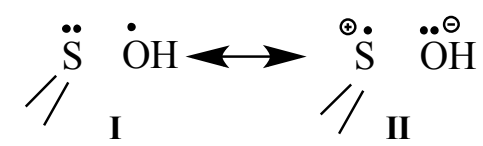

c)

Scheme 1.Two-structures Valence Bond resonating descriptions of 2c-3e bonding for: a) the $\left[\mathrm{R}_{2} \mathrm{~S} \therefore \mathrm{SR}_{2}\right]^{+}$cation dimer, b) the $[\mathrm{RS} \therefore \mathrm{SR}]^{-}$anion dimer, c) the neutral $\left[\mathrm{R}_{2} \mathrm{~S} \therefore \mathrm{OH}\right]$ adduct.

In the case of anionic and cationic three-electron bonded systems, each VB structure taken separately is generally only marginally stabilizing through pure electrostatic interactions with 
respect to the separate fragments at infinite distance, and thus the large overall stabilization energy (up to $\sim 60 \mathrm{kcal} / \mathrm{mol}$ in some cases) mainly comes from the large resonance energy arising from the mixing of the two VB structures together. This resonance energy stabilization could be interpreted as coming from the dynamical shift of charge between the two fragments, thus classifying this type of bond as a complete « charge shift bond ». ${ }^{79-81}$

One important condition for having a stable 2c-3e bond is that the two VB structures should be close in energy, because simple perturbation theory shows that the resonance energy between the two structures is inversely proportional to their energy difference. The ideal case occurs when the two structure are degenerated, as in the prototype cases of $\left[\mathrm{H}_{2} \mathrm{~S}\right]_{2}{ }^{+}$or $[\mathrm{RS}]_{2}{ }^{-}$already mentioned, a situation that can strictly happen only in case of anionic or cationic dimers composed of identical fragments.

Three-electron bonds are much less common in neutral systems, because in this case one VB structure is a neutral one and the second is necessarily a di-ionic structure, as displayed in scheme 1c) in the case of $\mathrm{S} \therefore \mathrm{O}$ bonding, so the two VB structures are usually largely separated in energy (note that in the following we will use the symbol " $\therefore$ ” originally proposed by Asmus ${ }^{2}$ to identify a resonating 2c-3e type of bonding). The two VB structures may reasonably be close in energy when the Ionization Potential (IP) of the fragment initially containing the lone pair is close to the Electron Affinity (EA) of the second (initially radical) fragment. In the case of a S. $\mathrm{O}$ adduct, it is when sufficiently donating substituents are bonded to the sulfur atom that this condition can be fulfilled. Otherwise, when the two VB structures are much different in energy, the system in its ground electronic state is basically described by the neutral VB structure only, i.e. it is an adduct stabilized by weak non-covalent interactions.

At the $a b$ initio BOVB level of theory, a two-structure wave function corresponding to the resonance mixing $\mathbf{I} \leftrightarrow \mathbf{I I}$ is variationally optimized, where $\mathbf{I}$ is the neutral VB structure and II the di-ionic one, as depicted in scheme 1c). Details about the BOVB method and the definition of the structure weights are provided in the SI. Assessing whether a true S $\therefore \mathrm{O} 2 \mathrm{c}-3 \mathrm{e}$ bonding or a weak adduct occurs in the case of $\mathrm{DMS}^{+}$could simply be done by inspecting the structure weights coming out of the BOVB wave function optimization. A true $2 \mathrm{c}-3 \mathrm{e}$ bonding will indeed be characterized by similar weights for the two structures, in the range of $\sim 50-70 \%$ (resp. $\sim 30$ - 
$50 \%$ ) for the major neutral VB structure (resp. minor di-ionic VB structure), whereas in the case of a weak non-covalent adduct the neutral structure will have a very largely dominant weight of $\sim 90 \%$ or more.

It is particularly important here to identify the nature of the interaction between DMS and ${ }^{\circ} \mathrm{OH}$, because it is only in cases where a $2 \mathrm{c}-3 \mathrm{e}$ is found, i.e. with similar weights on structures I and II, that the mechanism of heterolytic dissociation may takes places. Structure I corresponds to the electronic structure of the reactants indeed, DMS and ${ }^{\circ} \mathrm{OH}$, while structure II corresponds to the electronic structure of the products of the heterolytic dissociation, namely $\mathrm{DMS}^{\bullet+}$ and ${ }^{-} \mathrm{OH}$. When ${ }^{\circ} \mathrm{OH}$ attaches to the sulfur atom of DMS, if it is a weak non-covalent adduct that is formed, the super system ground state VB wave function will mainly be composed of structure I, which means that structure II only mixes marginally into the ground state wave function. Thus an excitation to an electronic state mainly composed of structure II, a prerequisite for the heterolytic dissociation pathway, would represent a too high of an energy barrier to overcome. On the other hand, if the interaction that takes place is a true $2 \mathrm{c}-3 \mathrm{e}$ one, that means structure II will mix strongly into the ground state VB wave function when the DMS and ${ }^{\circ} \mathrm{OH}$ approach together, and thus that the adduct can more easily dissociate into a state corresponding to structure II only, i.e. take the pathway of heterolytic dissociation to $\mathrm{DMS}^{\bullet+}$ and ${ }^{-} \mathrm{OH}$ fragments.

From the above analysis, we can infer that the larger the weight of structure II in the ground state VB wave function, the more likely the heterolytic dissociation mechanism becomes. Alternatively, a second more quantitative indicator is the energy difference $\Delta \mathrm{E}_{\mathrm{I} / \mathrm{II}}$ of the two $\mathrm{VB}$ structures that compose the multi-structures $\mathrm{VB}$ wave function $\psi_{\mathrm{VB}}$, as defined by equation 2:

$$
\Delta E_{I / I I}=E_{V B}(I I)-E_{V B}(I)
$$

Note that $E_{V B}(I)$ and $E_{V B}(I I)$ correspond to the energy of the structures I and II, respectively, each with their own set of orbitals optimized in two separate calculations, and distinct to the total multi-structure $\Psi_{\mathrm{VB}}$ where the two structures are mixed and are optimized (as well as their relative weights) in the presence of each other (see the SI for more details). As illustrated in scheme $2 \mathrm{a}$ ), a large $\Delta \mathrm{E}_{\mathrm{I} / \mathrm{II}}$ correspond to the case where the ionic structure $\mathbf{I I}$ is much higher in energy than the neutral structure I and thus does not mix much into the ground state wave 
function, so in such a case the ground state is essentially a neutral adduct and the heterolytic mechanism would be quite unlikely. On the other hand, in case where $\Delta \mathrm{E}_{\mathrm{I} / \mathrm{II}}$ is small, as illustrated in scheme $2 b)$ ), structure II will substantially mix into the ground state wave function, and thus the heterolytic mechanism could be reasonably envisaged.

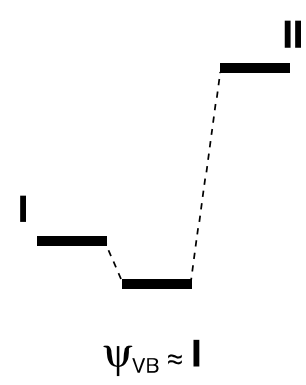

a)

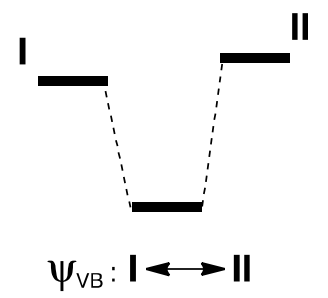

b)

Scheme 2.The two cases of adducts: a) large $\Delta \mathrm{E}_{\mathrm{I} / \mathrm{II}}$ energy difference between separate structures $\mathbf{I}$ and II leading to a weak mixing of II into $\psi_{\mathrm{VB}}$; b) small $\Delta \mathrm{E}_{\mathrm{I} / \mathrm{II}}$ leading to a large mixing of II into $\psi_{\mathrm{VB}}$.

In table 5 the BOVB total energy, structure weights and $\Delta \mathrm{E}_{\mathrm{I} / \mathrm{II}}$ are displayed, for both the BH\&HLYP/CCSD and MP2/CCSD optimized geometries (see "Computational details"). For the calculation of $\Delta \mathrm{E}_{\mathrm{I} / \mathrm{II}}$, the energies $\mathrm{E}_{\mathrm{VB}}(\mathrm{I})$ and $\mathrm{E}_{\mathrm{VB}}(\mathrm{II})$ correspond to the energies of each of the two VB structures computed separately, i.e. obtained from a separate wave function optimization calculation, thus providing for each one their own optimal set of orbitals. The BH\&HLYP/CCSD geometry corresponds to both the lowest BOVB and CCSD total energy. However, the energy difference between the two geometries is not very large, so the two different arrangement of the water cluster obtained from the BH\&HLYP and MP2 geometry optimizations could both be considered as representing two realistic arrangements. In both cases, the VB structures I and II comes out with similar weights from the BOVB calculations of the I $\leftrightarrow$ II resonance mixing, I being the dominant structure in the BH\&HLYP/CCSD geometry, while II is slightly more dominant in the MP2/CCSD geometry. The same trend is found when looking to the $\Delta \mathrm{E}_{\mathrm{I} / \mathrm{II}}$ energy difference. A value of only $16.8 \mathrm{kcal} / \mathrm{mol}$ is found for $\Delta \mathrm{E}_{\mathrm{I} / \mathrm{II}}$ when computed using the BH\&HLYP/CCSD geometry, which indicates that the two individual VB structures are rather close in energy; and it is found to be even as small as $2.8 \mathrm{kcal} / \mathrm{mol}$ when the MP2/CCSD geometry is used, showing that the two structures are almost degenerate in that case 
The BOVB method not being a routine electronic structure method requires theoretical expertise in Valence Bond theory and specific technical know-how to be properly used. Furthermore, the method remains quite computationally demanding, and thus is limited to the model systems studied so far. Thus it would be highly desirable to be capable of obtaining the same type of analysis from a more routine $a b$ initio wave function method. In the specific case of the $2 \mathrm{c}-3 \mathrm{e}$ bond, it is possible to retrieve an estimate of the weights of the two VB structures from the spin density analysis computed from any wave-function method. This is because, for a $2 c-3 e$ bond: i) each VB structure displays a different and distinct number of active electrons on the sulfur and oxygen centers and: ii) the spin density is essentially shared between the sulfur and oxygen atoms making the $2 \mathrm{c}-3 \mathrm{e}$ bond. Hence, the spin polarization is due to the three-electron bond and not from other electron pairs. The structure weights $\omega(\mathbf{I})$ and $\omega(\mathbf{I I})$, expressed in $\%$, may indeed be estimated using the spin densities of equation 3. Specifically $\rho(O)$ and $\rho(S)$ are the spin densities on oxygen and sulfur atoms, respectively, computed at any given level of theory. These weights are simply the renormalized spin densities.

$$
\begin{gathered}
\omega_{I}=100 \times \frac{\rho(O)}{\rho(S)+\rho(O)} \\
\omega_{I I}=100 \times \frac{\rho(S)}{\rho(S)+\rho(O)}
\end{gathered}
$$

The spin densities computed at the CCSD and BOVB levels of theory, along with the inferred structure weights calculated using equations 3 and 4, are displayed in table 6 . It can be noted that the BOVB weights estimated this way are remarkably close to the original Coulson-Chirgwin weights shown in table 5. This fully validates the approach of equation 3 and underlying approximation in the case of a $2 \mathrm{c}-3 \mathrm{e}$ bond. Let us remark that although CCSD and BOVB methods both include some electronic correlation, this is to a much larger extend for the CCSD method, so it is reasonable to consider that the latter method provides a more accurate description of the system. However, it is unfortunately impossible to estimate CCSD values for the $\Delta \mathrm{E}_{\mathrm{I} / \mathrm{II}}$ energy difference, as this quantity would require the computation of separate structure energies, which could only be provided by a method, like BOVB, capable of computing 
individual diabatic states. However, it is clear from the CCSD structure weights that, at this level of theory, the structure II comes out to be the major one, by a tiny amount when the BH\&HLYP/CCSD geometry is considered but more significantly when the MP2/CCSD geometry is used. This result clearly supports the possibility of a heterolytic dissociation mechanism.

----- insert table 6 near here -----

One can see from the previous data, that two different arrangements of the four water molecules surrounding the HO $\therefore$ DMS adduct while close in energy correspond to respective structures with weights differing by some $\sim 10 \%$. Such a sensitivity of the VB weights with respect to the first solvation shell vs. a much smaller sensitivity of the total energy was quite unexpected, and calls for further investigation.

In ambient temperature the water molecules dynamically move around the HO-DMS adduct, exploring configurations that are close in energy, so it is legitimate to try to answer the following questions: i) what is the overall range in variations of the structure I vs. II weights, ii) is there a situation with even more contrasted I vs. II weights, and: iii) what is the overall statistical significance of situations where the $\mathrm{S} \therefore \mathrm{O}$ bond is dominantly described by structure II, i.e. an electronic situation prone to heterolytic dissociation. To answer this question, the same structure weight estimation based on CCSD spin-density analysis were performed on a set of configurations with four water molecules extracted directly from the molecular dynamics, with a fixed SO bond length of $2.45 \AA$. These configurations selected were each more than 200 ps apart from each other in the molecular dynamics trajectory, which is sufficient to ensure that the snapshots are decorrelated. The results are displayed in table 7. Minimum potential energy snapshots tend to have two water molecules hydrogen bonded to the ${ }^{\circ} \mathrm{OH}$ moiety of the DMS adduct while the maximum potential energy snapshots tend to have none. The coordinates and figures of two snapshots, with either minimum or maximum potential energy, can be found in table S6 of the SI.

----- insert table 7 near here ----- 
In these snapshots, the three lowest in potential energy give the two weights of structure $\mathbf{I}$ and II to be equal or slightly favor structure II. The other three snapshots, which are significantly higher in potential energy, the weight of structure $\mathbf{I}$ is found to be slightly more dominant with the most extreme case being a 56.2/43.8 ratio. All in all, it can be concluded that the SO bond in the HO $\therefore$ DMS adduct incorporates a substantial amount of the diabatic electronic state corresponding to the products of an heterolytic dissociation $\left(\mathrm{HO}^{-}\right.$and $\left.\mathrm{DMS}^{\bullet+}\right)$, with a $\mathbf{I} / \mathbf{I I}$ ratio that could vary roughly between $\sim 60 / 40$ and $\sim 40 / 60$ depending on the dynamic arrangement of the water molecules belonging to the first solvation shell; and, consequently, that an heterolytic dissociation mechanism is a hypothesis that is backed up by this analysis.

\section{Conclusion.}

In this work we have revisited the oxidation of dimethyl sulfide by ${ }^{\bullet} \mathrm{OH}$ radical, by carefully taking into account explicit water molecules surrounding dimethyl sulfide (DMS), the hydroxyl radical and their adduct in the quantum calculations. The role of explicit water molecules were previously found to be important in another oxidation mechanism, namely the oxidation of DMS by hydrogen peroxide, however the previous study only considered the neutral reactants and products $^{42}$.

First, we have pointed out that in the formation of the $>\mathrm{S}-{ }^{\bullet} \mathrm{OH}$ the influence of the substituents of the sulfur atom is negligible, thus the choice of DMS to model larger molecules such as Met (notably in its extended conformation).

Second, for the three systems in our study, namely DMS, ${ }^{\bullet} \mathrm{OH}$ and their adduct [DMS-OH $]^{\bullet}$, we performed MD simulations with thousands of water molecules surrounding them, which allowed us to analyze the changes concerning mainly the first solvation shell. From these MD simulations, we extracted small clusters of water molecules most likely forming the first solvation shells, and used two different methodologies: i) QM/MM calculations, and ii) full quantum DFT calculations (BH\&HLYP) with an implicit solvent, to determine accurately what are the water molecules in direct interaction with the solvated molecule. Both methodologies agreed. The resulting minimal clusters were subsequently used in high level CCSD and BOVB calculations. 
Finally, BOVB a high level Valence Bond method was used to compute the weights of the two possible diabatic states that mix in the ground state wave function of DMS- ${ }^{\circ} \mathrm{OH}$, i.e. the ratio of the charged (ionic) diabatic structure $\left[\mathrm{DMS}^{\bullet+}-\mathrm{OH}^{-}\right]$to the neutral diabatic structure [DMS-OH$\left.{ }^{\bullet}\right]$. When the weights of the two diabatic structures are similar it corresponds to the existence of a resonant 2c-3e (two-center three-electron) bond between the sulfur atom of DMS and the oxygen atom of ${ }^{\bullet} \mathrm{OH}$. Meanwhile a substantially larger weight for the neutral diabatic state corresponds to a weakly bonded adduct. Our calculations revealed that the readily accessible configurations of water molecules in the first solvation shell modulate the covalent/ionic character of the adduct S-O bond noticeably. BOVB calculations on snapshots obtained directly from MD simulations suggest that the neutral/ionic character of the bond varies from approximately $40 / 60 \%$ to $60 / 40 \%$, depending on the instantaneous water configuration. We have shown that in the case of $3 \mathrm{e}-2 \mathrm{c}$ bonds, the structure weights can be estimated from the spin density on the atoms involved in the $3 \mathrm{e}-2 \mathrm{c}$ bond (i.e. the sulfur of DMS and oxygen of ${ }^{\circ} \mathrm{OH}$ ) computed at the MP2, BH\&HLYP or CCSD level, and that these estimates correlate well with the weights obtained from BOVB calculations. The results from these model calculations provide guidance for future investigations of oxidation reactions involving larger sulfur-containing biological molecules.

\footnotetext{
Supporting Information. Detailed description of the methodology for the molecular dynamics simulations (including solute geometries and force field parameters) and additional background information for the Valence Bond methods is included in the SI.
}

\section{ACKNOWLEDGMENT}

Pr. Wei Wu is gratefully thanked for making his XMVB program available to us. 


\section{REFERENCES}

1. Aruoma, O. I.; Halliwell, B., Molecular Biology of free radicals in human diseases. OICA International: 1998.

2. Asmus, K. D., Stabilization of oxidized sulfur centers in organic sulfides - radical cations and odd-electron sulfur-sulfur bonds. Acc. Chem. Res. 1979, 12, 436-442, and references therein.

3. Asmus, K. D., Sulfur-centered three-electron bonded radical species. 1990; Vol. 197, p 155-172, and references therein.

4. Chatgilialoglu, C., Free radical chemistry of sulfenic acids and their derivatives. In Sulphenic and derivatives, John Wiley \& Sons Ltd.: 1990; pp 549-569, and references therein.

5. Chatgilialoglu, C.; Castelhano, A. L.; Griller, D., Structures and optical-absorption spectra of some sulfuranyl radicals in solution. J. Org. Chem. 1985, 50, 2516-2518, and references therein.

6. Armstrong, D., Thermochemistry of Sulfur Radicals. In S-Centered Radicals, Alfassi, Z. B., Ed. Wiley: 1999.

7. Schoneich, C.; Bobrowski, K., Intramolecular hydrogen-transfer as the key step in the dissociation of hydroxyl radical adducts of (alkylthio)ethanol derivatives. J. Am. Chem. Soc. 1993, 115, 6538-6547, and references therein.

8. $\quad$ Hynes, A. J.; Stoker, R. B.; Pounds, A. J.; McKay, T.; Bradshaw, J. D.; Nicovich, J. M.; Wine, P. H., A mechanistic study of the reaction of $\mathrm{OH}$ with dimethyl-d(6) sulfide - direct observation of adduct formation and the kinetics of the adduct reaction with O-2. J. Phys. Chem. 1995, 99, 16967-16975, and references therein.

9. Hynes, A. J.; Wine, P. H.; Semmes, D. H., Kinetics and mechanism of oh reactions with organic sulfides. J. Phys. Chem. 1986, 90, 4148-4156, and references therein.

10. Baird, N. C., 3-electron bond. J. Chem. Educ. 1977, 54, 291-293.

11. Mozziconacci, O.; Mirkowski, J.; Rusconi, F.; Kciuk, G.; Wisniowski, P. B.; Bobrowski, K.; Houée-Levin, C., Methionine residue acts as a prooxidant in the $(\mathrm{OH})-\mathrm{O} \bullet$-induced oxidation of enkephalins. J. Phys. Chem.B 2012, 116, 12460-12472.

12. Ignasiak, M.; de Oliveira, P.; Levin, C. H.; Scuderi, D., Oxidation of methioninecontaining peptides by $(\mathrm{OH})-\mathrm{O} \bullet$ radicals: Is sulfoxide the only product? Study by mass spectrometry and IRMPD spectroscopy. Chem. Phys. Lett. 2013, 590, 35-40.

13. Scuderi, D.; Bergès , J.; de Oliveira, P.; Houée-Levin, C., Methionine one-electron oxidation: Coherent contributions from radiolysis, IRMPD spectroscopy, DFT calculations and electrochemistry. Radiat. Phys. Chem. 2016, 128, 103-111.

14. Bergès, J.; Trouillas, P.; Houée-Levin, C., Oxidation of protein tyrosine or methionine residues: From the amino acid to the peptide. In Cost Chemistry Cm0603-Melusyn Joint Meeting: Damages Induced in Biomolecules by Low and High Energy Radiations, Gauduel, Y. A.; Houée-Levin, C., Eds. 2011; Vol. 261.

15. Trouillas, P.; Bergès , J.; Houée-Levin, C., Toward understanding the protein oxidation processes: $(\mathrm{OH})-\mathrm{O} \bullet$ addition on tyrosine, phenylalanine, or methionine? Int. J. Quantum Chem. 2011, 111, 1143-1151.

16. Pilmé, J.; Luppi, E.; Bergès , J.; Houée-Levin, C.; de la Lande, A., Topological analyses of time-dependent electronic structures: application to electron-transfers in methionine enkephalin. J. Mol. Model. 2014, 20, 2368.

17. Bergès , J.; Kamar, A.; de Oliveira, P.; Pilmé, J.; Luppi, E.; Houée-Levin, C., Toward an understanding of the oxidation process of methionine enkephalin: A combined electrochemistry, 
quantum chemistry and quantum chemical topology analysis. J. Phys. Chem.B 2015, 119, 68856893.

18. Marino, T.; Soriano-Correa, C.; Russo, N., Oxidation mechanism of methionine by HO• radical: A theoretical study. J. Phys. Chem.B 2012, 116, 5349-5354.

19. Uranga, J.; Mujika, J. I.; Matxain, J. M., $\bullet \mathrm{OH}$ oxidation toward S- and $\mathrm{OH}-$ containing amino acids. J. Phys. Chem.B 2015, 119, 15430-15442.

20. Xipsiti, C.; Nicolaides, A. V., A computational study on the possible role of oxygen in the oxidation of methionine and dimethylsulfide initiated by $\mathrm{OH}$ radicals. Comput. Theor. Chem. 2013, 1009, 24-29.

21. Clark, T., Odd-electron delta-bonds. J. Am. Chem. Soc. 1988, 110, 1672-1678.

22. Gill, P. M. W.; Radom, L., Structures and stabilities of singly charged 3-electron hemibonded systems and their hydrogen-bonded isomers. J. Am. Chem. Soc. 1988, 110, 49314941.

23. Braïda, B.; Hazebroucq, S.; Hiberty, P. C., Methyl substituent effects in HnX therefore $\mathrm{XHn}(+)$ three-electron-bonded radical cations $(\mathrm{X}=\mathrm{F}, \mathrm{O}, \mathrm{N}, \mathrm{Cl}, \mathrm{S}, \mathrm{P} ; \mathrm{n}=1-3)$. An ab initio theoretical study. J. Am. Chem. Soc. 2002, 124, 2371-2378.

24. Braïda, B.; Thogersen, L.; Wu, W.; Hiberty, P. C., Stability, metastability, and unstability of three-electron-bonded radical anions. A model ab initio theoretical study. J. Am. Chem. Soc. 2002, 124, 11781-11790.

25. Fourré, I.; Silvi, B.; Sevin, A.; Chevreau, H., Topological characterization of threeelectron-bonded radical anions. J. Phys. Chem.A 2002, 106, 2561-2571.

26. Braïda, B.; Hiberty, P. C., A simplified Gaussian-2 scheme for determining electron affinities of covalent bonds. Application to the disulfide bond RS-SR ' (R, R ' = H, CH3, C2H5). J. Phys. Chem.A 2003, 107, 4741-4747.

27. Fourré, I.; Silvi, B., What can we learn from two-center three-electron bonding with the topological analysis of ELF? Heteroat. Chem. 2007, 18, 135-160.

28. Gamez, J. A.; Yanez, M., Asymmetry and electronegativity in the electron capture activation of the Se-Se bond: sigma(star)(Se-Se) vs sigma(star)(Se-X). J. Chem. Theory. Comput. 2010, 6, 3102-3112.

29. Gamez, J. A.; Yanez, M., FAAF (-) (A = O, S, Se, Te) or How electrostatic interactions influence the nature of the chemical bond. J. Chem. Theory. Comput. 2013, 9, 5211-5215.

30. Dumont, E.; Loos, P. F.; Assfeld, X., Effect of ring strain on disulfide electron attachment. Chem. Phys. Lett. 2008, 458, 276-280.

31. Geronimo, I.; Cheron, N.; Fleurat-Lessard, P.; Dumont, E., How does microhydration impact on structure, spectroscopy and formation of disulfide radical anions? An ab initio investigation on dimethyldisulfide. Chem. Phys. Lett. 2009, 481, 173-179.

32. Dumont, E.; Laurent, A. D.; Assfeld, X., Intersulfur distance is a key factor in tuning disulfide radical anion vertical UV-visible absorption. J. Phys. Chem. Lett. 2010, 1, 581-586.

33. Dupont, C.; Dumont, E.; Jacquemin, D., Superior performance of range-separated hybrid functionals for describing sigma* <- sigma UV-vis signatures of three-electron two-center anions. J. Phys. Chem. A 2012, 116, 3237-3246.

34. Fourré, I.; Bergès, J., Structural and topological characterization of the three-electron bond: The SO radicals. J. Phys. Chem. A 2004, 108, 898-906.

35. Fourré, I.; Bergès , J.; Braïda, B.; Houée-Levin, C., Topological and spectroscopic study of three-electron bonded compounds as models of radical cations of methionine-containing dipeptides. Chem. Phys. Lett. 2008, 467, 164-169. 
36. Becke, A. D.; Edgecombe, K. E., A Simple measure of electron localization in atomic and molecular-systems. J. Chem. Phys. 1990, 92, 5397-5403.

37. Savin, A.; Nesper, R.; Wengert, S.; Fassler, T. F., ELF: The electron localization function. Angew. Chem., Int. Ed. 1997, 36, 1809-1832.

38. Silvi, B., The spin-pair compositions as local indicators of the nature of the bonding. $J$. Phys. Chem. A 2003, 107, 3081-3085.

39. Silvi, B.; Savin, A., Classification of chemical-bonds based on topological analysis of electron localization functions. Nature 1994, 371, 683-686.

40. Barone, S. B.; Turnipseed, A. A.; Ravishankara, A. R., Reaction of OH with dimethyl sulfide (DMS) .1. Equilibrium constant for $\mathrm{OH}+\mathrm{DMS}$ reaction and the kinetics of the $\mathrm{OH} \bullet$ DMS+O-2 reaction. J. Phys. Chem. 1996, 100, 14694-14702.

41. Chu, J. W.; Brooks, B. R.; Trout, B. L., Oxidation of methionine residues in aqueous solutions: Free methionine and methionine in granulocyte colony-stimulating factor. J. Am. Chem. Soc. 2004, 126, 16601-16607.

42. Chu, J. W.; Trout, B. L., On the mechanisms of oxidation of organic sulfides by $\mathrm{H} 2 \mathrm{O} 2$ in aqueous solutions. J. Am. Chem. Soc. 2004, 126, 900-908.

43. Gu, M.; Turecek, F., The elusive dimethylhydroxysulfuranyl radical - an intermediate or a transition-state. J. Am. Chem. Soc. 1992, 114, 7146-7151.

44. Marciniak, B.; Bobrowski, K.; Hug, G. L.; Rozwadowski, J., Photoinduced electrontransfer between sulfur-containing carboxylic-acids and the 4-carboxybenzophenone triplet-state in aqueous-solution. J. Phys. Chem.1994, 98, 4854-4860.

45. McKee, M. L., Computational study of addition and abstraction reactions between $\mathrm{OH}$ radical and dimethyl sulfide - a difficult case. J. Phys. Chem.1993, 97, 10971-10976.

46. Ramirez-Anguita, J. M.; Gonzalez-Lafont, A.; Lluch, J. M., A theoretical study of the $\mathrm{DMS} \bullet \mathrm{OH}$ scavenging reaction by $\mathrm{OH}$. Its relevance in DMSO formation. Comput. Theor. Chem. 2011, 965, 249-258.

47. Turecek, F., The dimethylsulfide-hydroxyl radical reaction - an ab-initio study. J. Phys. Chem.1994, 98, 3701-3706.

48. Turnipseed, A. A.; Barone, S. B.; Ravishankara, A. R., Reaction of OH with dimethyl sulfide .2. Products and mechanisms. J. Phys. Chem.1996, 100, 14703-14713.

49. Wang, L. M.; Zhang, J. S., Addition complexes of dimethyl sulfide (DMS) and OH radical and their reactions with O-2 by ab initio and density functional theory. J. Mol. Struct.: Theochem 2001, 543, 167-175.

50. Williams, M. B.; Campuzano-Jost, P.; Cossairt, B. M.; Hynes, A. J.; Pounds, A. J., Experimental and theoretical studies of the reaction of the $\mathrm{OH}$ radical with alkyl sulfides: 1. Direct observations of the formation of the OH-DMS adduct-pressure dependence of the forward rate of addition and development of a predictive expression at low temperature. J. Phys. Chem.A 2007, 111, 89-104.

51. Antonczak, S.; Ruiz-Lopez, M. F.; Rivail, J. L., Ab initio analysis of water-assisted reaction mechanisms in amide hydrolysis. J. Am. Chem. Soc. 1994, 116, 3912-3921.

52. Cerón-Carrasco, J. P.; Requena, A.; Michaux, C.; Perpète, E. A.; Jacquemin, D., Effects of hydration on the proton transfer mechanism in the adenine-thymine base pair. J. Phys. Chem.A 2009, 113, 7892-7898.

53. Jacquemin, D.; Michaux, C.; Perpète, E. A.; Frison, G., Comparison of microhydration methods: protonated glycine as a working example. J. Phys. Chem. B 2011, 115, 3604-3613. 
54. Michaux, C.; Wouters, J.; Jacquemin, D.; Perpète, E. A., A theoretical investigation of the hydrated glycine cation energetics and structures. Chem. Phys. Lett. 2007, 445, 57-61.

55. Michaux, C.; Wouters, J.; Perpète, E. A.; Jacquemin, D., Modeling the microhydration of protonated alanine. J. Phys. Chem. B 2008, 112, 9896-9902.

56. Michaux, C.; Wouters, J.; Perpète, E. A.; Jacquemin, D., Microhydration of protonated glycine: An ab initio family tree. J. Phys. Chem. B 2008, 112, 2430-2438.

57. Inada, Y.; Mohammed, A. M.; Loeffler, H. H.; Rode, B. M., Hydration structure and water exchange reaction of nickel(II) ion: Classical and QM/MM simulations. J. Phys. Chem. A 2002, 106, 6783-6791.

58. Hofer, T. S.; Pribil, A. B.; Randolf, B. R.; Rode, B. M., Structure and dynamics of solvated $\mathrm{Sn}$ (II) in aqueous solution: An ab initio QM/MM MD approach. J. Am. Chem. Soc. 2005, 127, 14231-14238.

59. Hofer, T. S.; Rode, B. M.; Pribil, A. B.; Randolf, B. R., Simulations of liquids and solutions based on quantum mechanical forces. In Advances in Inorganic Chemistry: Theoretical and Computational Inorganic Chemistry, Vol 62, Van Eldik, R.; Harvey, J., Eds. 2010; Vol. 62, pp 143-175.

60. Cui, Q., Combining implicit solvation models with hybrid quantum mechanical/molecular mechanical methods: A critical test with glycine. J. Chem. Phys. 2002, $117,4720-4728$.

61. Gorb, L.; Asensio, A.; Tunon, I.; Ruiz-Lopez, M. F., The mechanism of formamide hydrolysis in water from ab initio calculations and simulations. Chem. - Eur. J. 2005, 11, 67436753.

62. Meng, X. J.; Zhao, H. L.; Ju, X. S., Influences of n (2-5) water molecules on the proton transfer in hydrated glycine complexes. Comput. Theor. Chem. 2012, 1001, 26-32.

63. Sunoj, R. B.; Anand, M., Microsolvated transition state models for improved insight into chemical properties and reaction mechanisms. Phys. Chem. Chem. Phys. 2012, 14, 12715-12736.

64. Yogeswari, B.; Kanakaraju, R.; Abiram, A.; Kolandaivel, P., Molecular dynamics and quantum chemical studies on incremental solvation of glycine. Comput. Theor. Chem. 2011, 967, 81-92.

65. Frisch, M. J.; Trucks, G. W.; Schlegel, H. B.; Scuseria, G. E.; Robb, M. A.; Cheeseman, J. R.; Scalmani, G.; Barone, V.; Mennucci, B.; Petersson, G. A., et al. Gaussian 09, Revision A.02, Gaussian, Inc.: Wallgford CT, 2009.

66. Tomasi, J.; Mennucci, B.; Cammi, R., Quantum mechanical continuum solvation models. Chem. Rev. 2005, 105, 2999-3093.

67. Braïda, B.; Hiberty, P. C.; Savin, A., A systematic failing of current density functionals: Overestimation of two-center three-electron bonding energies. J. Phys. Chem.A 1998, 102, 78727877.

68. Hiberty, P. C.; Humbel, S.; Byrman, C. P.; Vanlenthe, J. H., Compact valence-bond functions with breathing orbitals - application to the bond-dissociation energies of $\mathrm{F}_{2}$ and FH. $J$. Chem. Phys. 1994, 101, 5969-5976.

69. Hiberty, P. C.; Shaik, S., Breathing-orbital valence bond method - a modern valence bond method that includes dynamic correlation. Theor. Chem. Acc. 2002, 108, 255-272.

70. Official web site for the code XMVB: http://www.xmvb.org/ (accessed January 1, 2016) 
71. Song, L. C.; Mo, Y. R.; Zhang, Q. N.; Wu, W., XMVB*: A program for ab initio nonorthogonal valence bond computations. J. Comput. Chem. 2005, 26, 514-521.

72. Chen, Z. H.; Chen, X.; Wu, W., Nonorthogonal orbital based N-body reduced density matrices and their applications to valence bond theory. II. An efficient algorithm for matrix elements and analytical energy gradients in VBSCF method. J. Chem. Phys. 2013, 138, 164120.

73. Song, L.; Chen, Z.; Ying, F.; Song, J.; Chen, X.; Su, P.; Mo, Y.; Zhang, Q.; Wu, W. $X M V B$ 2.1: an ab initio non-orthogonal Valence Bond program; Xiamen University: Xiamen 361005, China, 2015.

74. Desiraju, G. R., A Bond by Any Other Name. Angew. Chem., Int. Ed. 2011, 50, 52-59.

75. Antonczak, S.; RuizLopez, M.; Rivail, J. L., The hydrolysis mechanism of formamide revisited: Comparison between ab initio, semiempirical and DFT results. J. Mol. Model. 1997, 3, 434-442.

76. Braïda, B.; Hiberty, P. C., Diatomic halogen anions and related three-electron-bonded anion radicals: Very contrasted performances of Møller-Plesset methods in symmetric vs dissymmetric cases. J. Phys. Chem. A 2000, 104, 4618-4628.

77. Braïda, B.; Lauvergnat, D.; Hiberty, P. C., Symmetry-breaking and near-symmetrybreaking in three-electron-bonded radical cations. J. Chem. Phys. 2001, 115, 90-102.

78. Pauling, L., The nature of the chemical bond. II. The one-electron bond and the threeelectron bond. J. Am. Chem. Soc. 1931, 53, 3225-3237.

79. Anderson, P.; Petit, A.; Ho, J. M.; Mitoraj, M. P.; Coote, M. L.; Danovich, D.; Shaik, S.; Braïda, B.; Ess, D. H., Protonated alcohols are examples of complete charge-shift bonds. J. Org. Chem. 2014, 79, 9998-10001.

80. Shaik, S.; Danovich, D.; Braïda, B.; Wu, W.; Hiberty, P. C., New landscape of electronpair bonding: Covalent, ionic, and charge-shift bonds. In Chemical Bond II: 100 Years Old and Getting Stronger; Mingos, D. M. P., Ed.; Springer: Switzerland, 2016; Vol. 170, pp 169-211.

81. Shaik, S.; Danovich, D.; Wu, W.; Hiberty, P. C., Charge-shift bonding and its manifestations in chemistry. Nat. Chem. 2009, 1, 443-449. 

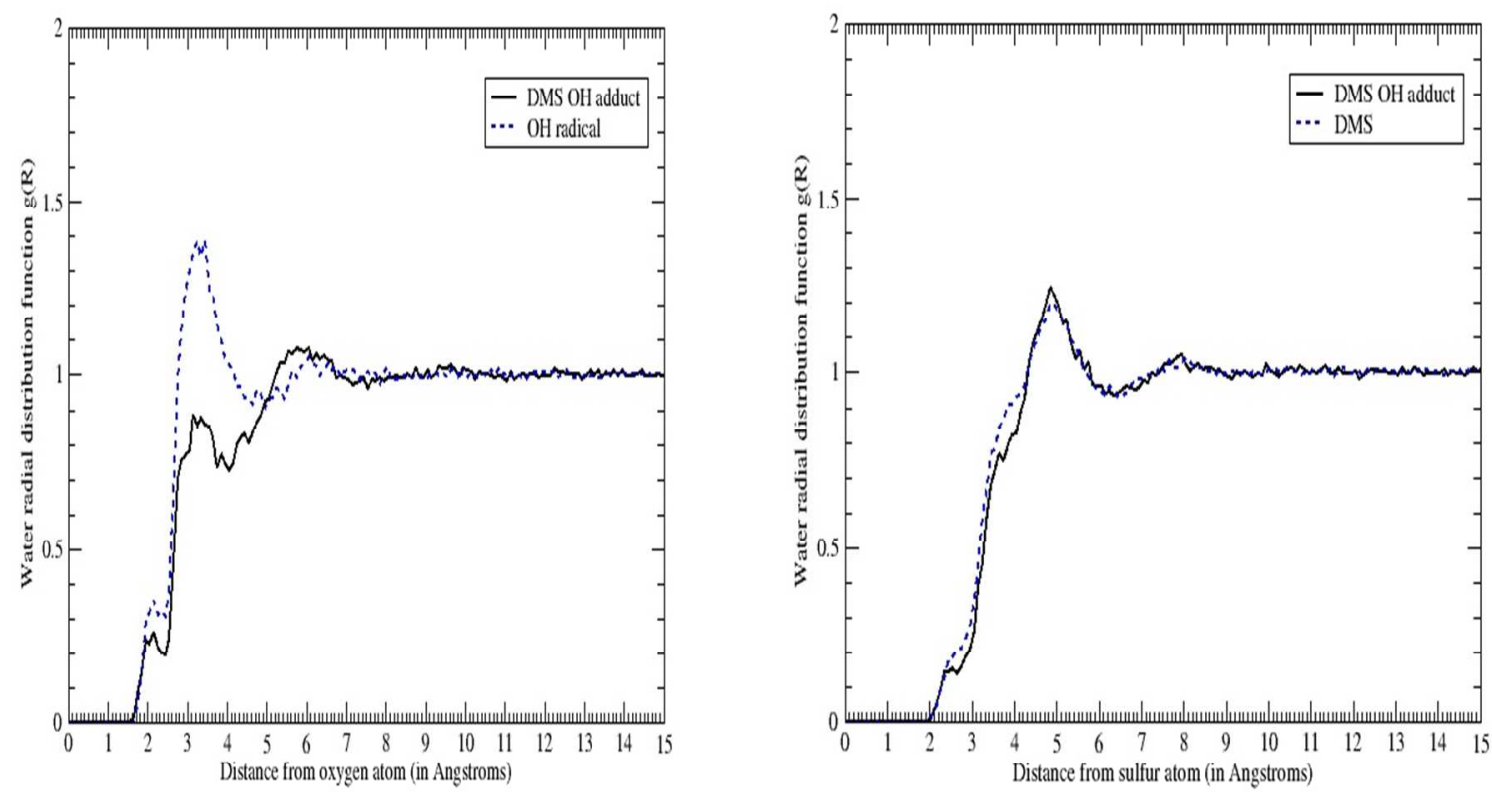

Figure 1: Radial distribution of water around: a) the oxygen atom of ${ }^{\bullet} \mathrm{OH}$ in the DMS- ${ }^{\circ} \mathrm{OH}$ (solid line) and in the hydroxyl radical alone (dotted line) ; b) the sulfur atom of DMS in DMS${ }^{\circ} \mathrm{OH}$ (solid line) and in the DMS fragment alone (dotted line). 


\begin{tabular}{|c|c|c|c|}
\hline Methods & Models & $\rho \mathrm{S} \quad \rho \mathrm{O}$ & ds-o \\
\hline \multirow{4}{*}{$\mathrm{Pbe} 0 / 6-31 \mathrm{~g}(\mathrm{~d})$} & " $\mathrm{CH}_{3}$ " & $0.38 \quad 0.64$ & 2.315 \\
\hline & " $\mathrm{CO}_{2} \mathrm{CH}_{3}$ " & $0.37 \quad 0.65$ & 2.315 \\
\hline & ' $\mathrm{CO}_{2} \mathrm{HNH}_{2}$ '" & $0.37 \quad 0.65$ & 2.315 \\
\hline & "CONH" & $0.37 \quad 0.65$ & 2.315 \\
\hline \multirow{4}{*}{ BH\&HLYP/6-31g(d) } & " $\mathrm{CH}_{3}$ " & $0.21 \quad 0.83$ & 2.491 \\
\hline & "' $\mathrm{CO}_{2} \mathrm{CH}_{3}$ " & $0.20 \quad 0.84$ & 2.504 \\
\hline & ' $\mathrm{CO}_{2} \mathrm{HNH}_{2}$ ' & $0.20 \quad 0.84$ & 2.504 \\
\hline & "CONH" & $0.20 \quad 0.84$ & 2.504 \\
\hline \multirow{4}{*}{$\begin{array}{l}\text { BH\&HLYP/6- } \\
311+g(d, p)\end{array}$} & " $\mathrm{CH}_{3}$ " & $0.38 \quad 0.64$ & 2.363 \\
\hline & " $\mathrm{CO}_{2} \mathrm{CH}_{3}$ " & $0.38 \quad 0.65$ & 2.363 \\
\hline & ' $\mathrm{CO}_{2} \mathrm{HNH}_{2}$ ' & $0.38 \quad 0.65$ & 2.364 \\
\hline & "CONH" & $0.38 \quad 0.65$ & 2.362 \\
\hline
\end{tabular}

Table 1. The distances of the $\mathrm{SO}$ bond and the spin densities of $\mathrm{S}$ and $\mathrm{O}$ for various substituents of S, using different DFT functionals and basis sets, and embedded in the implicit solvent CPCM. 


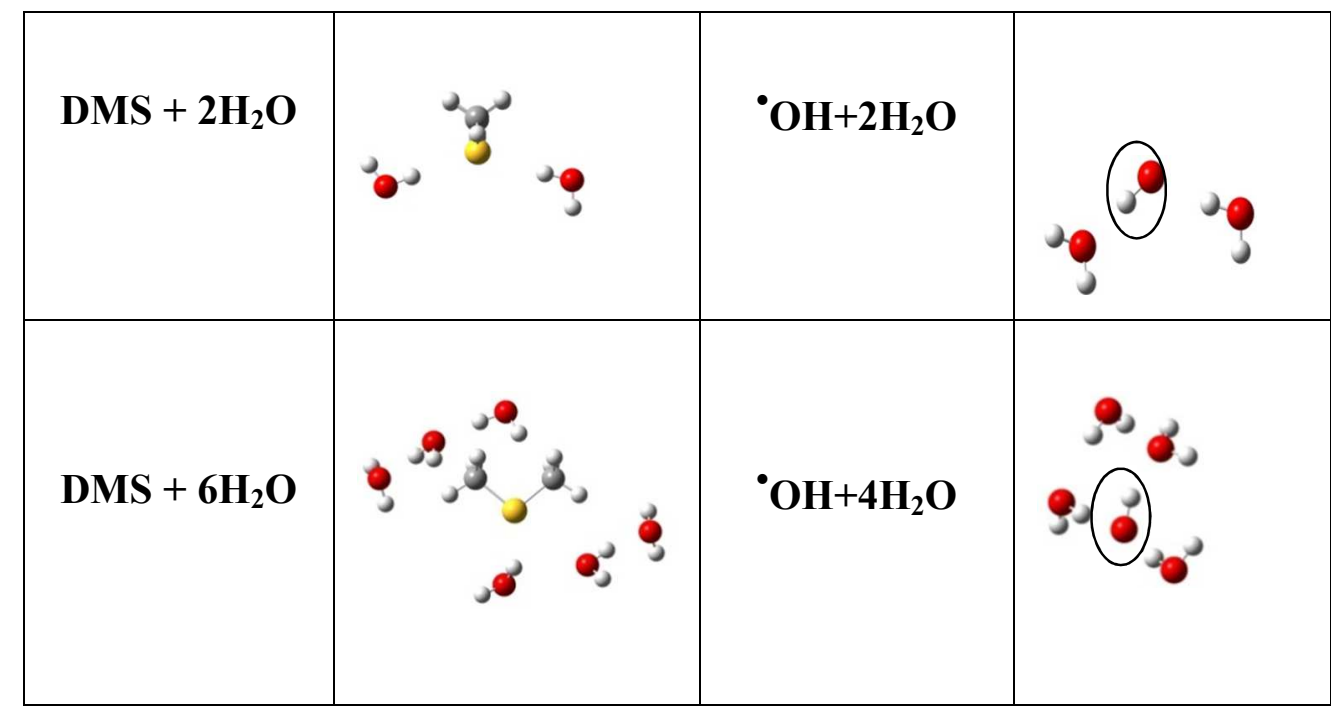

Table 2. Optimized geometries of the water molecules around solutes (DMS and ${ }^{\circ} \mathrm{OH}$ ) at the BH\&HLYP/6-311+G(d,p)/CPCM level of theory. 


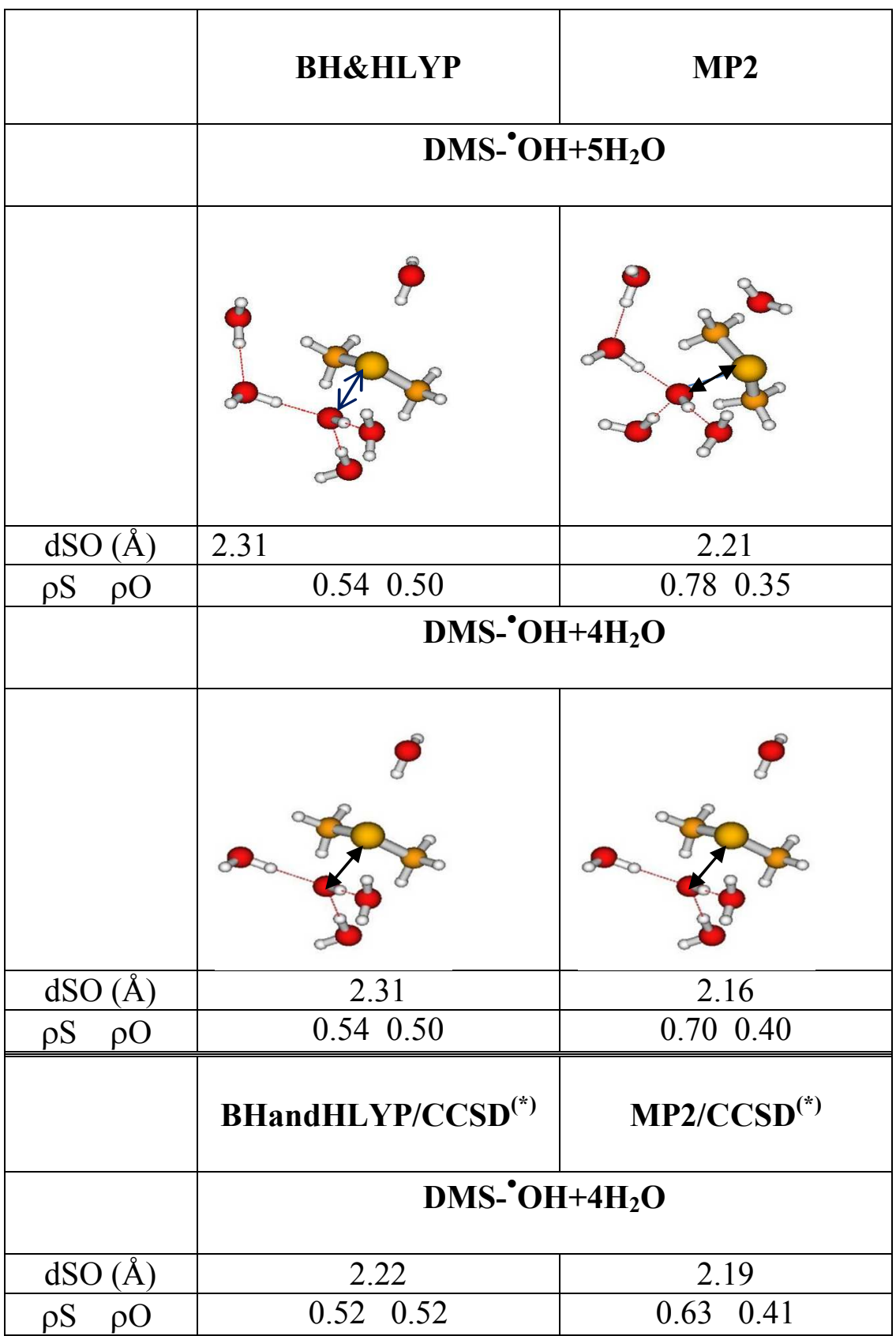

Table 3. Bond Dissociation Energies in $\mathrm{kcal} / \mathrm{mol}$ of the DMS- ${ }^{\circ} \mathrm{OH}$ adduct with implicit CPCM solvation only (left), and of the DMS- ${ }^{\circ} \mathrm{OH}+4 \mathrm{H}_{2} \mathrm{O}$ super system (center and right) further embedded into CPCM. The 6-311+G(d,p) basis set has been used, and the geometries are those optimized at each given level of theory. Arrows represent the S-O bond and dotted lines represent hydrogen bonds present in the super system. 


\begin{tabular}{|c|c|c|c|}
\hline & DMS- ${ }^{\circ} \mathrm{OH}$ & \multicolumn{2}{|c|}{ DMS- ${ }^{-} \mathrm{OH}+4 \mathrm{H}_{2} \mathrm{O}$} \\
\hline & BH\&HLYP & BH\&HLYP & MP2 \\
\hline $\begin{array}{l}\mathrm{BDE} \\
\mathrm{kcal} / \mathrm{mol}\end{array}$ & 5.51 & 7.42 & 13.11 \\
\hline
\end{tabular}

Table 4. Bond Dissociation Energies of the SO bond in the adduct DMS- ${ }^{\circ} \mathrm{OH}$ are calculated with two models of solvent: implicit one (CPCM) alone and with 4 water molecules for BH\&HLYP and MP2 


\begin{tabular}{|l|c|c|c|}
$\begin{array}{c}\text { Optimized } \\
\text { geometry }\end{array}$ & $\begin{array}{c}\Delta \mathbf{E}_{\mathbf{B O V B}} \\
(\mathrm{kcal} / \mathrm{mol})\end{array}$ & $\begin{array}{c}\text { Weights } \\
\mathbf{I} / \mathbf{I I} \\
\mathbf{( \% )}\end{array}$ & $\begin{array}{c}\Delta \mathbf{E}_{\mathbf{I} / \mathbf{I I}} \\
(\mathrm{kcal} / \mathrm{mol})\end{array}$ \\
\hline $\mathrm{MP} 2 / \mathrm{CCSD}$ & 6.3 & $49.5 / 50.5$ & 2.8 \\
\hline $\mathrm{BH} \& H L Y P / C C S D$ & 0.0 & $57.3 / 42.7$ & 16.8 \\
\hline
\end{tabular}

Table 5. Relative $\mathrm{BOVB}$ total energy $\left(\Delta \mathrm{E}_{\mathrm{BOVB}}\right)$ using the most stable geometry as the energy zero, Chirgwin Coulson structure weights (see SI), and the energy difference of the individual structures $\Delta \mathrm{E}_{\mathrm{I} / \mathrm{II}}$ (see text), computed on the MP2/CCSD and BH\&HLYP/CCSD optimized geometries respectively. 


\begin{tabular}{|l|c|c||c|c|}
\hline \multicolumn{1}{|c|}{ Geometry } & \multicolumn{2}{c||}{ CCSD } & \multicolumn{2}{c|}{ BOVB } \\
\hline & $\boldsymbol{\rho}(\mathbf{S}) / \boldsymbol{\rho}(\mathbf{O})$ & $\boldsymbol{\omega}(\mathbf{I}) / \omega(\mathbf{I I})$ & $\boldsymbol{\rho}(\mathbf{S}) / \boldsymbol{\rho}(\mathbf{O})$ & $\boldsymbol{\omega}(\mathbf{I}) / \omega($ II $)$ \\
\hline $\mathrm{MP} 2 / \mathrm{CCSD}$ & $0.627 / 0.407$ & $39.4 / 60.6$ & $0.492 / 0.481$ & $49.4 / 50.6$ \\
\hline BH\&HLYP/CCSD & $0.522 / 0.518$ & $49.8 / 50.2$ & $0.411 / 0.563$ & $57.8 / 43.2$ \\
\hline
\end{tabular}

Table 6.Spin densities on sulfur and oxygen, and corresponding structure weights defined as renormalized spin densities from equations (3), at both the CCSD and BOVB levels, computed using the MP2/CCSD and BH\&HLYP/CCSD optimized geometries respectively. 


\begin{tabular}{|l|c|c|c|}
\hline \multicolumn{1}{|c|}{ Snapshots } & $\begin{array}{c}\Delta \mathbf{E}_{\mathbf{B O V B}} \\
(\mathrm{kcal} / \mathrm{mol})\end{array}$ & $\begin{array}{c}\text { Spin density } \\
(\mathbf{S} / \mathbf{O})\end{array}$ & $\begin{array}{c}\text { Weights I/II(\%) } \\
\text { via equation (1) }\end{array}$ \\
\hline min E npt snapshot & 0.0 & $0.533 / 0.510$ & $48.9 / 51.1$ \\
\hline min E nvt snapshot 1 & 0.0 & $0.533 / 0.517$ & $49.2 / 50.8$ \\
\hline min E npt snapshot & 0.8 & $0.515 / 0.535$ & $50.9 / 49.1$ \\
\hline max E npt snapshot & 9.7 & $0.440 / 0.552$ & $55.6 / 44.4$ \\
\hline max E nvt snapshot 2 & 13.0 & $0.476 / 0.574$ & $54.7 / 45.3$ \\
\hline max E nvt snapshot & 9.3 & $0.458 / 0.587$ & $56.2 / 43.8$ \\
\hline
\end{tabular}

Table 7.Relative BOVB total energies $\left(\mathrm{E}_{\mathrm{BOVB}}\right)$ using the most stable geometry as the energy zero, computed from snapshots selected from the Molecular Dynamics (see text). Spin densities on sulfur and oxygen, and structure weights defined as renormalized spin densities from equations (3), at both the CCSD and BOVB levels. Coordinates and figures of snapshots 1 and 2 are summarized in tableS6. 


\section{TOC GRAPHICS :}

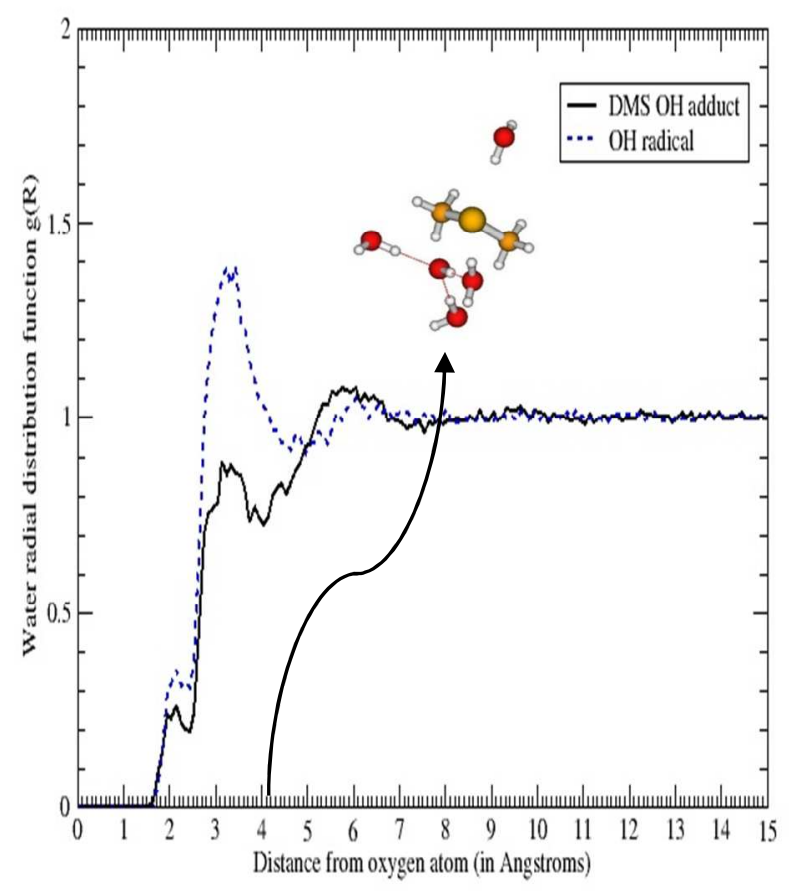

ACS Paragon Plus Environment 